\title{
CONTRATOS INTERNACIONAIS DE FRANQUIA
}

Everton Luiz Szychta ${ }^{1}$

\section{RESUMO}

Os contratos internacionais de franquia devem ser estudados devido às suas particularidades e ao seu grande uso. O mercado de franquias internacionais se expandiu bastante nos primeiros anos de século $X X I$, e continua crescendo. No comércio internacional, o tipo de franquia mais utilizado é a franquia mestre. A franquia representa uma parceria e pode proporcionar diversos benefícios aos contratantes, como segurança, economia, conquista de mercado e fortalecimento da marca. Entretanto, devem-se analisar as cláusulas de um contrato como esse, pois elas tratam de assuntos que podem determinar o sucesso ou o fracasso de uma rede de franquias, como: a divisão das responsabilidades, lucros e despesas; o fornecimento de suporte técnico; a utilização de patentes; e como a solução de problemas judiciais. Por isso, um contrato de franquia deve ser elaborado conforme o princípio da boa-fé e sob a idéia de parceria, sociedade.

\section{ABSTRACT}

International franchise contracts must be studied because of their particularities and because of their wide uses. The international franchising business has grown a lot during XXI century first years. The most used international franchise contracts are the master franchise model ones. Franchise is like an association and may offer many benefits to the parts, like security, economy, expanded markets and also strengthen brand-names. However, we should study the contract clauses because they hold topics that may decide the success or failure of the franchise, such as: responsibilities and money distribution, the technical auxiliary supply, patents utilization and judicial

\footnotetext{
1 Acadêmico da Faculdade de Direito da Universidade Federal do Paraná e integrante do Núcleo de Estudos em Direito Internacional da Universidade Federal do Paraná.
}

Revista Brasileira de Direito Internacional, Curitiba, v.2, n.2, jul./dez.2005 
problems solution. Thus, one franchise contract has to be created considering good faith principle and an association idea.

PALAVRAS-CHAVE: LEI - CONTRATOS - FRANQUIA

KEY WORDS: LAW - CONTRACTS - FRANCHISE

\section{SISTEMA DE FRANQUIA}

Nos últimos anos, inúmeras empresas estrangeiras abriram franquias no Brasil. Segundo pesquisa realizada pela Associação Brasileira de Franchising (ABF) e pelo Instituto Franchising, o Brasil registrou um crescimento de $9 \%$ no faturamento das franquias em 2004. As franquias movimentaram $\mathrm{R} \$ 31,6$ bilhões no mesmo ano ${ }^{2}$. Dentre outros contratos, os de franquia podem ser considerados um dos mais importantes. Algumas das maiores corporações mundiais utilizam redes de franquias, o que gera mais lucro para elas. Porém, não se pode esquecer das relações jurídicas dos contratos de franquia, que, apesar de trazerem inúmeras vantagens para ambas as partes, se não forem bem analisados, podem se transformar em problemas e preocupações. Deve haver muito cuidado, sobretudo, nos contratos internacionais, pois eles apresentam outras peculiaridades que devem ser ponderadas com cautela.

Segundo Marcelo Cherto ${ }^{3}$, o contrato de franquia nasceu como uma prática de comércio que visava estimular e promover as trocas mercantis no século XIX. O principal objetivo era ampliar as participações no mercado sem a necessidade de grandes investimentos. Com o passar do tempo, mudanças nos modos de produção, inovações tecnológicas, mudanças no cenário do comércio mundial, o sistema de franquias foi ganhando espaço por se mostrar eficiente e apto às novas condições do mercado. Espalhou-se pelos Estados

2 ASSOCIAÇÃO BRASILEIRA DE FRANCHISING (ABF); INSTITUTO FRANCHISING. Estatísticas do desempenho do franchising brasileiro em 2004. Disponível em: $<$ http://www.portaldofranchising.com.br $>$. Acesso em: 12 out. 2005.

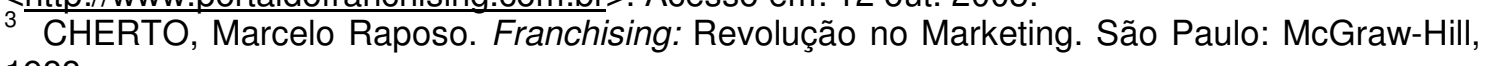
1988.

Revista Brasileira de Direito Internacional, Curitiba, v.2, n.2, jul./dez.2005 
Unidos e pelo mundo, a partir da criação da Singer Sewing Machine Company (1860), seguida pela General Motors (1898), Coca-cola (1899), Hertz-Rent-aCar (1921), dentre outras ${ }^{4}$. Fortaleceu-se em 1955, com a criação da famosa rede McDonald's. Inicialmente as franquias operavam basicamente em um sistema de distribuição ou engarrafamento de produtos.

A globalização foi um fator preponderante para que houvesse integração econômica e abertura de mercados, o que permitiu a instalação de subsidiárias de empresas globais, multinacionais, para explorar atividades econômicas em outros territórios. Foi através do contrato de franquia que se pôde atingir um número bastante alto de pessoas, colocando-se à disposição delas produtos padronizados, que têm seus custos diminuídos, devido à maior facilidade na fabricação.

A franquia é geralmente proveitosa tanto para quem adquire os direitos de franquia, o franqueado, como para quem cede esses direitos, o franqueador. Segundo Maria Helena Diniz ${ }^{5}$, de um lado, o franqueador pode ampliar seus negócios com baixos investimentos, tornar sua marca mais forte e competitiva. Do outro, o franqueado tem a possibilidade de abrir um negócio com menos riscos, amparado por pessoas mais experientes, por uma marca e produtos que já apresentaram um relativo sucesso. $O$ consumidor, por fim, pode usufruir de produtos com bons padrões de qualidade e de bom atendimento.

A franquia começou a ser usada há algumas décadas no Brasil, em lanchonetes, hotéis, postos de gasolina, por exemplo. As franquias internacionais entraram no país em grande escala. Como os empresários estrangeiros não conhecem bem o varejo brasileiro, fazem parcerias comerciais com empreendedores do país. Para estes empresários, que conhecem o mercado nacional, apresenta-se uma oportunidade conveniente de se fazer um bom negócio e de sobreviver no mercado. O sucesso pode depender bastante do modelo de franquia adotado pelo franqueador.

\footnotetext{
${ }^{4}$ DINIZ, Maria Helena. Tratado Teórico e Prático dos Contratos. V. 4. São Paulo: Saraiva, 1996, p. 43.

5 DINIZ, Maria Helena. Tratado Teórico e Prático dos Contratos. v. 4. São Paulo: Saraiva, 1996, p. 45.
}

Revista Brasileira de Direito Internacional, Curitiba, v.2, n.2, jul./dez.2005 
A franquia se baseia na concessão de uma marca ou produto para ser explorada por terceiros, que mantém a logomarca e os padrões do franqueador. Na década de 60, surgiu a escola de idiomas Yázigi. No fim da década de 70, houve um aumento grande no número de franquias no Brasil, principalmente de lanchonetes oriundas dos Estados Unidos, e ainda surgiram diversas franquias nacionais, como O Boticário, Água de Cheiro e Bob's. Mas, foi na década de 80 que realmente se firmou o sistema. Em 1987, criou-se a Associação Brasileira de Franchising ${ }^{6}$, que passou a anunciar balanços e a expansão dos mercados de franquia, chamando a atenção de muitos empresários ${ }^{7}$. No ano seguinte surgiu Instituto Franchising.

O sistema de franquias precisou sofrer ajustes para melhor atender às necessidades dos brasileiros, adequando-se à realidade do país, ao mercado consumidor, por isso alguns produtos tiveram correções nos projetos de marketing e ajustes nos preços.

No Brasil, após discussões e incertezas sobre as vantagens ou não de se ter uma lei regulando os contratos de franquia, a Lei $n .0$ 8.955, que trata do o assunto, foi aprovada. Antes da lei, o contrato de franquia era um contrato comum, ficava sujeito às normas dos contratos gerais. Segundo o art. 2.. $\mathrm{da}$ Lei 8.955/94, franquia é:

\footnotetext{
"O sistema pelo qual um franqueador cede ao franqueado o direito de uso da marca ou patente, associado ao direito de distribuição exclusiva ou semiexclusiva de produtos ou serviços e, eventualmente, também o direito de uso de tecnologia de implantação ou administração do negócio ou sistema operacional desenvolvidos ou detidos pelo franqueador, mediante remuneração direta ou indireta, sem que, no entanto, fique caracterizado vínculo empregatício."
}

A principal função dessa regulamentação jurídica é estabelecer normas para garantir que o público seja bem informado, de forma transparente e clara, sobre as condições de uma oferta de negócio.

Para Maria Helena Diniz, eis o conceito de franquia:

\footnotetext{
6 ASSOCIAÇÃO BRASILEIRA DE FRANCHISING. Disponível em: $<$ http://www.portaldofranchising.com.br $>$. Acesso em 15 fev. 2006.

7 DINIZ, Maria Helena. Tratado Teórico e Prático dos Contratos. v. 4. São Paulo: Saraiva, 1996, p. 43.
}

Revista Brasileira de Direito Internacional, Curitiba, v.2, n.2, jul./dez.2005 
"Franquia ou franchising é o contrato pelo qual uma das partes (franqueador ou franchisor) concede, por certo tempo, à outra (franqueado ou franchisee) o direito de comercializar com exclusividade, em determinada área geográfica, serviços, nome comercial, título de estabelecimento, marca da indústria ou produto que lhe pertence, com assistência técnica permanente, recebendo em troca, certa remuneração."8

Segundo a International Franchise Association, a operação de franquia é uma relação entre o franqueador e o franqueado, na qual aquele deve manter um interesse ininterrupto no negócio deste, em quesitos como treinamento e know-how. O franqueado faz um investimento financeiro em seu próprio negócio e opera sob um nome comercial comum, de acordo com um padrão estabelecido pelo franqueador. ${ }^{9}$ Um contrato de franquia apresenta características bastante típicas, como assistência técnica obrigatória por parte do franqueador, concessão de uso de marca, territorialidade e não caracteriza vínculo empregatício, por exemplo.

Na concepção de Marcelo Cherto ${ }^{10}$, a franquia é um:

\begin{abstract}
"Método e um arranjo para a distribuição de produtos e, ou, serviços. Juridicamente, se implementa através de um contrato pelo qual um detentor de um nome ou marca, de uma idéia, de um método ou tecnologia, segredo ou processo, proprietário ou fabricante de um certo produto ou equipamento, mais know-how a ele relacionado (o franchisor ou o franqueador), outorga a alguém dele jurídica e economicamente independente, licença para explorar esse nome ou marca (...)."
\end{abstract}

A franquia é uma operação comercial, é realizada entre comerciantes, em que um deles dispõe de um produto e o outro o comercializa, por exemplo. Assim, o contrato de franquia é considerado um contrato mercantil, pois ambas as empresas são comerciais. O contrato é amplo e engloba tanto as características de um contrato de prestação de serviços, como as de um contrato de distribuição de produtos.

O contrato de franquia se distingue dos contratos de concessão mercantil com exclusividade, dos contratos de fornecimento e até dos contratos de distribuição porque sua característica essencial é a licença do uso

\footnotetext{
${ }^{8}$ Idem 7.

9 SIMÃO FILHO, Adalberto. Franchising: Aspectos Jurídicos e Contratuais. 2. ed. São Paulo: Atlas, 1997, p. 28.

${ }_{10}$ CHERTO, Marcelo Raposo. Franchising: Revolução no Marketing. São Paulo: McGraw-Hill, 1988, p. 04.
}

Revista Brasileira de Direito Internacional, Curitiba, v.2, n.2, jul./dez.2005 
da marca e a prestação de serviços da concedente ao concessionário. Além disso, o fornecedor é obrigado a prestar assistência, comercial ou técnica, ao comprador, que possui independência relativa, agindo por conta própria e não como um representante do produtor.

Existem também diversos tipos de franquia. Muitos autores apresentam suas próprias classificações dos tipos de franquia. Para Maria Helena Diniz ${ }^{11}$, há três tipos: a franquia industrial ou lifreding (licensing franchising export e direct investiment); franquia de comércio ou distribuição; e franquia de serviços, englobando os serviços hoteleiros.

O primeiro tipo é mais utilizado, para Mendez e Lehnisch ${ }^{12}$, em franquias internacionais, que não podem ou não desejam fabricar seus produtos em escala industrial para distribuir mundialmente, devido ao ônus com transporte. Assim, faz-se um acordo em que o franqueador não precisa se preocupar com patentes e coisas básicas, e, em contrapartida, obtém o retorno através de royalties pagos sobre a fabricação e construção da fábrica. Para Maria Helena Diniz, é um contrato em que o franqueador assume o compromisso de ajudar na construção de uma unidade industrial para o franqueado, transmitindo a tecnologia, exigindo segredos a respeito dos métodos de fabricação, concedendo a utilização da marca e provendo assistência técnica. Ou seja, o franqueado fabrica e comercializa seus produtos, com assessoria do franqueador. É muito utilizado por empresas alimentícias e automobilísticas, como a Coca-Cola e a Audi.

Já a franquia de comércio ou distribuição é o contrato que tem por objetivo a disseminação e reprodução de lojas padronizadas, com o fim de distribuir e comercializar artigos similares bem aceitos no mercado, como as lanchonetes Habib's.

$\mathrm{Na}$ franquia de serviços, o franqueador ensina $\mathrm{o}$ franqueado a reproduzir e vender as prestações de serviços que ele inventou. Segundo Simão Filho, ele "coloca à disposição do franqueado uma forma original,

\footnotetext{
11 DINIZ, Maria Helena. Tratado Teórico e Prático dos Contratos. v. 4. São Paulo: Saraiva, 1996.

12 MENDEZ, Max de; LEHNISCH, Jean Pierre. Como Fazer da Franquia um Bom Negócio. Nobel, 1991.
}

Revista Brasileira de Direito Internacional, Curitiba, v.2, n.2, jul./dez.2005 
pessoal e diferente de prestação de serviços". ${ }^{13}$ Isso ocorre no setor hoteleiro, como nas redes íbis, Mercuree Arccor; em escolas de idiomas; academias; lavanderias, como a 5 àSec; restaurantes; e lanchonetes, como a Burger King e McDonald's.

Para Simão Filho, as franquias ainda podem ser divididas em: individual, de conversão, combinada, mista, master, córner, associativa, financeira, multifranquia, multimarcas, de nova instalação, de desenvolvimento de área, itinerante, de representação e solidária.

Quando uma empresa franqueadora decide expandir seu negócio para outros países, ela pode fazer isso de diversas formas: por uma joint-venture com uma empresa do país a que se destina, abrindo uma filial, concedendo uma franquia diretamente a uma empresa local ou adotando o sistema de master franquia.

No último caso, a empresa desenvolve uma rede de unidades franqueadas que cubra grandes áreas territoriais, como um país inteiro ou parte dele. No comércio internacional o tipo de franquia mais utilizado é a franquia mestre (master franchise) ou master franquia, por satisfazer melhor ambas as partes. Nesse caso, o franqueador original do produto ou serviço delega a uma empresa local, de outro país, o direito de subfranquear, visando expandir internacionalmente sua marca. É um licenciamento de franqueados industriais e comerciais em uma região.

Para isso, conforme Marcelo Cherto ${ }^{14}$, é necessário dividir o território estrangeiro em áreas ou regiões, onde as empresas intermediárias, do país local, tornar-se-ão subfranqueadoras. O subfranqueador contrata outras empresas locais, através de franquia, para explorarem e desenvolverem diretamente a marca ali. Seria uma espécie de franquia indireta, pois um franqueador original estrangeiro cede a uma empresa de outro país, previamente selecionada, o direito de utilizar e repassar o uso de sua marca e seu know-how para terceiros. Isso gera uma série de outras franquias no

\footnotetext{
13 SIMÃO FILHO, Adalberto. Franchising: Aspectos Jurídicos e Contratuais. 2. ed. São Paulo: Atlas, 1997.

${ }_{14}$ CHERTO, Marcelo Raposo. Franchising: Revolução no Marketing. São Paulo: McGraw-Hill, 1988.
}

Revista Brasileira de Direito Internacional, Curitiba, v.2, n.2, jul./dez.2005 
território, partindo do franqueador original, passando pelo franqueado-mestre, até se chegar ao franqueado final, em seu ponto de venda ou fabricação.

No Brasil, esse tipo de franquia ainda é bastante novo. As franquias internacionais estariam sujeitas às legislações e à cultura do país em que se desenvolvem. Devido às diferenças culturais, lingüísticas, jurídicas e de mercado, além do fator financeiro, o empresário estrangeiro geralmente prefere delegar a um empresário local a tarefa de criar novas franquias ali. A franquia se desdobra, usualmente, em um contrato principal, celebrado entre 0 franqueador e o master franqueado, e diversos subcontratos, celebrados entre o master franqueado e os franqueados locais.

O subfranqueador está sujeito à legislação da mesma forma que o franqueador, devido à Lei 8.955/94, que, em seu art. 9.- , institui que todos os dispositivos dirigidos ao franqueador, aplicam-se também ao subfranqueador. Segundo o art. 9. da Lei 8.955/94: "Para os fins desta lei, o termo franqueador, quando utilizado em qualquer de seus dispositivos, serve também para designar o subfranqueador, da mesma forma que as disposições que se refiram ao franqueado aplicam-se ao subfranqueado".

Essa classificação das franquias tem apenas o objetivo de explicar melhor o sistema de franquia e suas características, demonstrando as diversas variáveis dos modelos de contratos de franquia. Há autores que apresentam outras classificações para os contratos de franquia.

\section{CONTRATO DE FRANQUIA}

No Brasil não existe um contrato padrão de franquia, ficando cada empresa responsável pela redação de seu próprio contrato, respeitando a lei que rege o sistema de franquias no país ${ }^{15}$.

Como ocorre em qualquer outro contrato, inicialmente, as partes devem se aproximar e tomar conhecimento uma das intenções da outra, como afirma Irineu Strenger ${ }^{16}$. A empresa que oferece a franquia deve disponibilizar, por

\footnotetext{
${ }^{15}$ MILITELLI, Marcos Aurélio. Franchising - Como Tornar sua Empresa uma Franquia. São Paulo: SEBRAE-SP, 1996.

${ }^{16}$ STRENGER. Irineu. Contratos Internacionais do Comércio. 4. ed. São Paulo: LTr, 2003.
}

Revista Brasileira de Direito Internacional, Curitiba, v.2, n.2, jul./dez.2005 
meio de Circular de Oferta, todas as informações relevantes que permitam ao possível franqueado eleger o negócio que the seja mais viável, indicando o valor a ser investido, a rentabilidade média prevista para o negócio e o prazo provável de retorno do capital investido, como prevê a Lei 8.955/94. Feito o contrato inicial ou não, cada interessado deve investigar o outro, o franqueador examina a condição financeira e a estrutura que o franqueado possui, este, por sua vez, avalia as condições de mercado do produto e as imposições feitas pelo franqueado. Após essa etapa inicial, as partes iniciam a discussão sobre a elaboração das cláusulas contratuais.

As negociações preliminares não geram necessariamente obrigações para as partes. Segundo Sílvio Rodrigues ${ }^{17}$, na fase das negociações preliminares, não há contrato, não se estabelecem quaisquer laços convencionais. Porém, não pode haver um abandono arbitrário ou injustificado das negociações preliminares, pois há uma expectativa legítima da conclusão do contrato. Há obrigações, nas hipóteses de culpa aquiliana, quando for provado que uma das partes obteve um dano por promessas não cumpridas da outra antes da celebração do contrato, ou se a ruptura for decorrência de um comportamento desleal, abusivo de uma das partes. Nessa situação, cabe uma indenização à parte prejudicada. As negociações devem seguir o princípio da boa-fé, que faz parte da responsabilidade civil.

Inicialmente, os contratos internacionais de franquia são como os demais contratos internacionais, na fase da formação do contrato há uma certa responsabilidade das partes sobre fatos ou atos que causem prejuízos à outra parte.

Algumas empresas preferem fazer o pré-contrato de franquia, que, segundo o art. 462 do Código Civil brasileiro de 2002, "deve conter todos os requisitos essenciais ao contrato a ser celebrado". A grande vantagem do précontrato, é que ele não é um mero protocolo de intenções, mas gera direitos e

17 RODRIGUES, Sílvio. Direito Civil: dos contratos e das declarações unilaterais da vontade. 9.ed. V. 3. Editora: Saraiva. 1980, p. 65-66.

Revista Brasileira de Direito Internacional, Curitiba, v.2, n.2, jul./dez.2005 
obrigações para ambas as partes, que são responsáveis por seus atos, segundo Luciana Marques de Paula ${ }^{18}$.

Os contratos de franquia, por serem reflexos de uma relação complexa e bastante abrangente, devem abordar, muitas vezes, diversos assuntos, o que gera diversas cláusulas. Estas podem se diferenciar de contrato para contrato, dependendo, principalmente, da qualidade dos produtos e da discussão das partes. Por isso, não há tipos únicos e determinados de contrato. Para Marcelo Cherto $^{19}$, entretanto, há algumas cláusulas que são essenciais nos contratos de franquia, e, por isso, aparecem na maioria deles. São elas: a que determina o prazo; a forma de remuneração; as taxas da franquia; quotas de venda; delimitação de território; zona de exclusividade; cessão da marca e know-how; rescisão e cancelamento do contrato. Há, ainda, cláusulas menos significativas, que são: a que obriga o franqueado a cumprir um horário de funcionamento da loja; a do direito do franqueador de fazer visitas imprevisíveis ao estabelecimento para fiscalizá-lo; a que estipula uma quantidade mínima de vendas dos produtos dos franqueados; a que determina que o franqueado só venderá produtos fabricados, autorizados ou indicados pelo franqueador; as que dispõem sobre a publicidade dos produtos, disposição visual dos funcionários e do estabelecimento.

No entanto, a maioria das empresas, atualmente, tem adotado o sistema de contrato de adesão. É aquele contrato em que as cláusulas foram estabelecidas previamente por apenas uma das partes e não são passíveis de alteração ou discussão pela outra. A única possibilidade dessa parte seria aceitar ou não o conteúdo das cláusulas. Normalmente, os contratos de adesão são mais vantajosos para as franqueadoras, que padronizam seu trabalho e seu tratamento com as franqueadas, significando, ainda, para ambas as partes, uma redução nos custos do processo e no tempo que o contrato levaria para ser concluído. Entretanto, dessa forma, o franqueado se vê sem direito de decidir a respeito do contrato. Por isso, o contrato de adesão

\footnotetext{
18 PAULA, Luciana Marques de. O que Analisar no Pré-Contrato de Franquia. Disponível em: <http://www.aol.com.br/franchising/dicas/0021.adp> . Acesso em: 16 fev. 2006.

19 CHERTO, Marcelo Raposo. Franchising: Revolução no Marketing. São Paulo: McGraw-Hill, 1988.
}

Revista Brasileira de Direito Internacional, Curitiba, v.2, n.2, jul./dez.2005 
deve ser feito com bastante habilidade, para não intimidar possíveis parceiros de negócio e arruinar os interesses do redator do contrato ${ }^{20}$.

Com relação às clausulas de um contrato de franquia, todos eles possuem uma cláusula de remuneração visto que a própria franquia é uma relação que envolve trocas e proveito econômico. O franqueador inicialmente cobra a taxa de franquia ou de filiação do franqueado. Estão englobados nessa taxa, a importância da cessão da franquia, o que é opcional, e os custos do auxílio prestado, por parte do franqueador, para que o franqueado se estabeleça. É cobrada também uma taxa mensal do franqueado ou taxa de royalties, estando sujeita às vendas do mês anterior. Esse valor corresponde à remuneração pelo uso da marca nos produtos, pela reposição de estoque e pela assistência mensal que o franqueador presta. Em alguns casos, também se cobram taxas por publicidade, mas para que a franquia não se torne muito onerosa, alguns franqueadores abrem mão dessa taxa.

A cláusula que determina o prazo em que o contrato estará em vigor, define se ele será um contrato de prazo determinado ou indeterminado. Não há um tempo mínimo para a duração desse tipo de contrato. Fica a cargo das partes decidirem o prazo de duração do contrato. Pelo bom senso, de acordo com Carla de $\mathrm{Marco}^{21}$, o prazo de um contrato de franquia deve ser, pelo menos, suficiente para garantir ao franqueado o retorno do capital investido no negócio, além de sua margem de lucro.

Um contrato de franquia apresenta bilateralidade, é realizado entre duas empresas; consensualidade, pois produz efeitos imediatos pela simples manifestação da vontade dos contratantes; e o caráter pessoal, a empresa que oferece a franquia escolhe quem ela quiser para the ceder a concessão, e depois da escolha, não se pode mudar. Isso traz segurança para ambas as partes.

\footnotetext{
20 RODRIGUES, Sílvio. Direito Civil: dos contratos e das declarações unilaterais da vontade. 9.ed. V. 3. Editora: Saraiva. 1980, p. 45-50.

21 MARCO, Carla Fernanda. Contrato de Franchising e seus Aspectos Internacionais. Revista Meio Jurídico. São José do Rio Preto, ano V, n.ํ50, p.52, 2001.
}

Revista Brasileira de Direito Internacional, Curitiba, v.2, n.2, jul./dez.2005 


\subsection{PECULIARIDADES}

Uma das características do contrato de franquia é que se pode, através dele, esquematizar uma rede de distribuição de produtos a baixo custo, sem a necessidade de abrir filiais ou subsidiárias e se podem comercializar exclusivamente produtos reconhecidos.

Por ser o contrato de franquia um arranjo de dois contratos, de distribuição e prestação de serviços, ele tem como objeto tanto o produto como a técnica. Quanto aos produtos, o franqueador cede a marca e o know-how de comercialização. Quanto à técnica, ela é fornecida para a organização, gerenciamento e administração do negócio, como analisa Maria Helena Diniz $^{22}$. Será fixada no contrato a abrangência da assistência técnica, da assistência contábil, e da estrutural, que são as mais usuais. A assistência técnica auxilia o franqueado quanto à organização empresarial, ao uso de programas de computadores, treinamento de funcionários e técnicas de marketing. Enfim, toda a experiência do franqueador poderá ficar à disposição da outra parte. A assistência estrutural auxilia na montagem das instalações. Resumidamente serve para planejar e montar a loja, de acordo com padrões da empresa. $\mathrm{Na}$ assistência contábil, o franqueador fiscaliza e ajuda o franqueado a administrar as finanças da loja ou fábrica, auxiliando a preservar a imagem, a saúde financeira da marca, diminuindo os riscos de falência. Ainda podem ser ofertadas assistências em relação a maquinários, instalações, manutenção, material de propaganda, manual de franquia, dentre outras.

Não há vínculo empregatício nos contratos. O franqueado tem autonomia jurídica e financeira ${ }^{23}$. A autonomia não é absoluta, é relativa, regulada pelos termos contidos no contrato consolidado e pelas regras nos manuais de franquia. $O$ contrato também pode impor restrições administrativas

\footnotetext{
22 DINIZ, Maria Helena. Tratado Teórico e Prático dos Contratos. v. 4. São Paulo: Saraiva, 1996.

${ }^{23}$ CHERTO, Marcelo Raposo. Franchising: Revolução no Marketing. São Paulo: McGraw-Hill, 1988, p. 4.
}

Revista Brasileira de Direito Internacional, Curitiba, v.2, n.2, jul./dez.2005 
ao franqueado. Porém, as partes são pessoas distintas e se responsabilizam individualmente por seus atos.

A exclusividade do espaço é de extrema importância, principalmente para o franqueado, pois delimita o seu espaço de atuação e o ingresso de outra franquia da rede àquela zona em que ele se encontra. Evita-se, assim, a saturação do mercado e distribui-se de forma melhor o produto comercializado. Essa disposição deverá estar bem explicitada no contrato, regulando a abrangência dos limites territoriais e as indenizações a serem pagas pelo não cumprimento da regra.

Outra característica do contrato de franquia é que somente o franqueador, alguém licenciado ou autorizado por ele, é que pode repor os bens a serem comercializados pelo franqueado. Isso ocorre porque o sistema de franquia exige uma homogeneidade na rede de distribuição. Os produtos devem obedecer a certos padrões, garantindo, assim a estabilidade na qualidade do produto. Caso existam abusos por parte do franqueado, impondo preços abusivos em cima dos produtos provisionados, o franqueado deve exigir mudanças na maneira de provisionar, licenciando ou autorizando outras empresas a forneceram o material. Ao atender às críticas do franqueado, o franqueador enfatizará o compromisso assumido e possibilitará preços mais acessíveis aos franqueados e aos consumidores finais.

O know-how deverá ser objeto de transferência no contrato. O knowhow pode ser entendido como um conjunto de conhecimentos, regras e práticas desenvolvidas pelo franqueador, sem patentes, oriundas da experiência pessoal. A cláusula contratual que regular esse assunto poderá ser feita de maneira que o conhecimento seja mantido em absoluto segredo e estabelecerá as penas devido à rescisão da cláusula e à indenização por perdas e danos. Quando o franqueado receber autorização para utilizar a marca, logotipo, sinal do franqueador, ele deverá fazê-lo com boa-fé e honra, veicular a marca à idéia de qualidade e bom atendimento, pois é a marca que, muitas vezes, leva o consumidor a ter confiança em um certo produto ou 
serviço ${ }^{24}$. Caso a empresa que concede a franquia tenha patentes registradas no Instituto Nacional de Propriedade Intelectual (INPI) e queira disponibilizá-las às empresas a ela filiadas, deverá dispor no contrato, detalhadamente, como isso deverá ser feito, por meio de um desdobramento do contrato de franquia em um contrato de licença para o franqueado, conforme as normas do INPI, como afirma Maria Helena Diniz ${ }^{25}$.

\section{EFEITOS JURÍDICOS}

Os motivos que levam ao fim do contrato são: expiração do prazo convencionando pelas pares; rescisão unilateral ${ }^{26}$, por descumprimento das obrigações contratuais ou quando os atos praticados por uma das partes prejudiquem a outra, devendo ser pedida e provada a rescisão por transgressão do contrato; ou bilateral, por cláusulas que permitam a uma das partes pedir a extinção, sem justa causa; e através da anulabilidade.

Normalmente, um contrato de franquia tem um tempo de duração previsto, mas também há cláusulas de renovação das obrigações conforme a vontade das partes. Caso seja descumprida alguma cláusula ou haja erro quanto à realidade da franquia, quando na prática as coisas acontecem diferentemente do que foi acordado anteriormente, ferindo algum princípio, como falta de pagamento, quebra de sigilo, falta de assistência técnica, ocultação de lucros, dentre outras, ocasiona-se o término do contrato. Como no caso das franquias há uma parceria comercial, a melhor solução é se fazer um acordo, para que possa ser mantida a parceria, a não ser no caso da falha cometida ser tal que não viabilize mais sua continuação.

Nos contratos internacionais, as soluções para os litígios são mais complicadas. Se um franqueado tiver problemas com um franqueador estrangeiro, surgirá a questão da legislação aplicável. Por isso, "é preciso estudar a cláusula de lei aplicável em conjunto com a cláusula de eleição de

\footnotetext{
${ }^{24}$ CHERTO, Marcelo Raposo. Franchising: Revolução no Marketing. São Paulo: McGraw-Hill, 1988 , p. 85.

${ }^{25}$ DINIZ, Maria Helena. Tratado Teórico e Prático dos Contratos. v. 4. São Paulo: Saraiva, 1996 , p. 45.

${ }^{26}$ Idem 25, p. 54.
}

Revista Brasileira de Direito Internacional, Curitiba, v.2, n.2, jul./dez.2005 
foro e a cláusula arbitral". ${ }^{27}$ A maioria dos contratos internacionais de franquia é contrato de adesão, principalmente os de master franquia, em que há uma probabilidade extremamente grande de que ele seja feito conforme a legislação e o foro daquele país onde fica a sede da empresa, e qualquer conflito deverá ser resolvido dentro desses aspectos. Isso com certeza trará desvantagens para um master brasileiro, ou qualquer que seja a nacionalidade do franqueado, se ocorrer algum problema, pois ele terá que resolvê-lo em um país estrangeiro e com uma lei estrangeira. No Brasil, a regra de conexão utilizada para os contratos internacionais é estabelecida pelo art. 9.. da Lei de Introdução ao Código Civil:

\footnotetext{
“Art. 9.': Para qualificar e reger as obrigações, aplicar-se-á a lei do país em

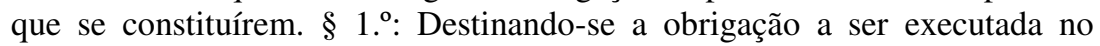
Brasil e dependendo de forma essencial, será esta observada, admitidas as peculiaridades da lei estrangeira quanto aos requisitos extrínsecos do ato. $\S$ 2. ${ }^{\circ}$ : A obrigação resultante do contrato reputa-se constituída no lugar em que residir o proponente."
}

A doutrina brasileira defende, de modo geral, que em se tratando de contratos internacionais, quando apenas uma das partes for domiciliada no exterior, ou cujos efeitos forem produzidos dentro do território nacional, prevalecerá o foro e a legislação brasileira, isso não ocorreria, apenas se as partes dispusessem o contrário no contrato. Assim, deve-se ter precaução quanto à autonomia da vontade para escolher a lei aplicável ao contrato, algo que não é expressamente permitido pela legislação brasileira. Também se deve analisar a questão da eleição de foro, pois há casos em que a justiça brasileira é competente, segundo o art. 88 do Código de Processo Civil, mesmo quando o foro escolhido é estrangeiro, o que leva a ação à total imprevisibilidade ${ }^{28}$.

\footnotetext{
27 ARAÚJO, Nádia de. Contratos Internacionais e a Jurisprudência Brasileira: Lei Aplicável, Ordem Pública e Cláusula de Eleição de Foro. In: João Grandino Rodas (coord.). Contratos Internacionais. 3. ed. rev., atual. e ampl. São Paulo: Editora Revista dos Tribunais, 2002, p. 198.

28 ARAÚJO, Nádia de. Contratos Internacionais e a Jurisprudência Brasileira: Lei Aplicável, Ordem Pública e Cláusula de Eleição de Foro. In: João Grandino Rodas (coord.). Contratos Internacionais. 3. ed. rev., atual. e ampl. São Paulo: Editora Revista dos Tribunais, 2002, p. 198.
}

Revista Brasileira de Direito Internacional, Curitiba, v.2, n.2, jul./dez.2005 
Outra questão importante se refere às responsabilidades perante os consumidores. O Código de Defesa do Consumidor versa sobre as responsabilidades pelo produto e pelo serviço, nos seus art. 12 a 17. Conforme o tipo de franquia adotado poder-se-á afirmar de quem é a responsabilidade por danos ao consumidor. Em franquias de produto, por exemplo, o franqueado é um mero revendedor do produto, que é adquirido com o fabricante e repassado para o consumidor final. Qualquer problema relacionado à linha de montagem, fabricação, manipulação, apresentação informações sobre o produto, fica a cargo do franqueador. Se for uma franquia formatada, onde o franqueador transfere técnicas de produção, administração e comercialização, somente o franqueado responderá pelos danos. Mas, para garantir o cumprimento das obrigações com terceiros, o Código de Defesa do Consumidor, no art. 34, estabelece que o fornecedor do produto também é solidário para com os atos de seus representantes. Quando não for acordado nada no contrato, a responsabilidade fica a cargo das duas empresas, não importando de quem seja a culpa. Nesses casos, a maioria das ações é proposta contra o franqueador. Porém, se o franqueado ficar encarregado de fabricar o produto final através de uma fórmula fornecida pelo franqueador, somente aquele responde perante terceiros.

Outro assunto bastante discutido é se as despesas com pagamentos de taxas iniciais e mensais com royalties e know-how da empresa que adquiriu a franquia poderiam ser deduzidos do imposto de renda. Prevalece a idéia de que somente os contratos registrados no Instituto Nacional de Propriedade Intelectual poderiam ser deduzidos do imposto de renda.

O franqueador pode, por dificuldades e problemas ocorridos no desempenho de sua atividade comercial, estar sob falência ou em dificuldades financeiras. Isso refletirá na rede de franqueados, quando iniciar um procedimento de recuperação judicial, conforme prevê a Lei n. ${ }^{0}$ 11.101/2005. Nesse caso, o franqueador deve informar a sua relação com as franquias, informar o grau de independência entre as empresas, para que os franqueados também não quebrem. Há uma grande fragilidade na posição de todos os envolvidos com a empresa. Por isso, deve haver compreensão entre os 
parceiros comerciais para que a crise possa ser superada por todos. Os franqueados podem, por exemplo, deixar de rescindir os contratos devido à falta de assistência ou irregularidades na entrega dos serviços, para ajudar a franqueadora. Se a quebra do franqueador for declarada por sentença, o franqueador perderá a disponibilidade de seus negócios. Para que os franqueados não quebrem junto, deve haver muita cautela, principalmente do poder público para que se tente continuar o negócio através da administração por parte de um administrador judicial. Os franqueados também podem formar uma associação para demonstrar que o negócio ainda é viável, bem como eles podem tomar medidas previstas anteriormente para que o franqueador saia da situação de falência.

No caso de dificuldade financeira de um franqueado, o processo é bem mais simples. Em alguns contratos estabelece-se, em cláusula, que caso seja requerida uma recuperação judicial do franqueado, o contrato será rescindido automaticamente. Porém, esse ato não estaria de acordo com os princípios do sistema de franquias, que seriam de parceria e reciprocidade. Em algumas franquias é usual que se cobrem taxas para formar um fundo de assistência financeira aos franqueados, administrado por alguém escolhido pelos eles mesmos. Outras franquias prestam assistência financeira direta ao franqueado para superar a crise, recebendo a importância de volta depois da passagem do momento de dificuldade.

\section{CONTRATOS DE MASTER FRANQUIA}

Nos contratos do tipo franquia mestre, mais utilizados no âmbito internacional, uma empresa estrangeira faz um contrato como uma empresa local, que será subfranqueadora de novas empresas (subfranqueadas) e estas têm a possibilidade de abrir uma franquia utilizando a marca da empresa estrangeira. Não haverá relação direta entre a empresa estrangeira e as empresas subfranqueadas locais. Porém, haverá uma relação de hierarquia nos contratos, há um contrato entre a franquia-mestre e a franqueadora estrangeira e um subcontrato, entre a franquia mestre e a subfranqueada, que 
estará subordinado ao principal. Será uma relação trilateral. Apesar de um vínculo indireto, há uma relação jurídica entre 0 franqueador e o subfranqueado. A empresa intermediária terá um grau alto de independência ou autonomia operacional, pois ela conhece o mercado de seu país, além disso, é ela quem tem a incumbência de adaptar o sistema de franquia aos costumes locais e à realidade da região.

Muitos cuidados devem ser tomados ao se realizar esse tipo de contrato, principalmente com relação à escolha do sócio, às condições de mercado e às diferenças socioculturais ${ }^{29}$. Com relação às cláusulas, as essenciais são: as obrigações dos contratantes, delimitação territorial, uso da marca, término do contrato, e principalmente, regras para a resolução dos litígios, como eleição de foro, lei aplicável e cláusula arbitral.

No que se refere ao foro e à lei aplicável, a lei mais justa de ser aplicada ao subfranqueado seria a nacional, visto que eles devem cumprir as maiores obrigações, porém, não é o que acontece na prática. Assim, está se tornando cada vez mais freqüente o uso da mediação e da arbitragem nos contratos de master franquia, se assim as partes dispuserem no contrato.

A mediação consiste, segundo José Cretella $\mathrm{Neto}^{30}$, na aproximação dos protagonistas do litígio, a seguir, o mediador propõe as bases para o desenvolvimento das negociações e intervém durante o processo com o objetivo de conciliar as partes, mas sem impor uma solução.

Para Irineu Strenger ${ }^{31}$, a arbitragem é "o sistema de solução de pendências, desde pequenos litígios pessoais até grandes controvérsias empresariais ou estatais, em todos os planos do Direito, que expressamente não estejam incluídos pela legislação". $\mathrm{Na}$ arbitragem comercial, as partes estipulam submeter seus problemas ao julgamento de particulares de sua escolha. A Lei n.ํ 9.307/96, que dispõe sobre a arbitragem, afirma que, para os contratos de adesão, a cláusula só terá eficácia se o aderente designar a

\footnotetext{
29 CHERTO, Marcelo Raposo. Franchising: Revolução no Marketing. São Paulo: McGraw-Hill, 1988, p. 74.

30 CRETELLA NETO, José. Arbitragem Internacional: o Significado Peculiar do Instituto no Contexto do Mecanismo de Solução de Controvérsias da Organização Mundial do Comércio. Revista de Direito Internacional e Economia. N. - 9, out./dez. 2004.

${ }^{31}$ STRENGER, Irineu. Arbitragem Comercial Internacional. São Paulo: LTr, 1996, p. 33.
}

Revista Brasileira de Direito Internacional, Curitiba, v.2, n.2, jul./dez.2005 
arbitragem ou se concordar com sua instituição, desde que haja uma assinatura especialmente para aquela cláusula, expressa em documento anexado.

Em casos incomuns em que uma quebra contratual é feita pelo franqueador, são tomadas atitudes como a compra dos direitos de uso da marca pelos franqueados ou suas associações. O rompimento de um contrato de franquia mestre traz importantes conseqüências. Geralmente, para evitar a ligação direta entre o franqueador e as inúmeras subfranquias de uma região que pouco conhece. A empresa estrangeira elege outra para assumir o lugar de franquia mestre, além de acionar a empresa anterior por rescisão contratual, não deixando, assim, os subfranqueados sem assistência. Os subfranqueados devem ter seus direitos de utilização de marca e técnicas preservadas, visto que eles não têm culpa pelo fim do contrato e receberam suas autorizações legitimamente. As maiores empresas de franquia do mundo incluem uma cláusula no contrato de franquia-mestre, que trata da rescisão contratual do subfranqueador, estabelecendo que imediatamente os contratos entre subfranqueados e subfranqueador passem a ser diretos entre 0 franqueador e os subfranqueados, de maneira provisória. Foi o que fez o McDonald's com a Genex- Mc Donald's, um master franqueado da antiga lugoslávia. As soluções para o franqueador, além dessa, são de abrir uma filial ou joint-venture no local ou de firmar contratos individuais com cada subfranqueado para evitar os riscos da quebra de cláusula de assistência ao subfranqueado. Se não houvesse nenhuma previsão contratual sobre a continuidade do sistema de franquias no país depois de uma possível quebra de contrato de master franquia, por culpa deste, a princípio os subfranqueados teriam direito à indenização do franqueador, devido ao fato de que os subfranqueados realizam o contrato com boa-fé e que o subfranqueador era um representante legítimo do franqueador estrangeiro.

\section{CONCLUSÃO}

Revista Brasileira de Direito Internacional, Curitiba, v.2, n.2, jul./dez.2005 
O franchising deve ser encarado pelos contratantes como uma união comercial, visando objetivos em comum. $O$ consumidor final se beneficia do sistema de franquia, desfrutando da qualidade e da padronização dos preços, produtos e serviços oferecidos pelas redes.

A análise dos diversos aspectos que compõem os contratos de franquia, e de suas peculiaridades, permite uma maior compreensão do que representa esse contrato. São esses aspectos que tornam os contratos mais atraentes e práticos para os empresários, que o buscam como um meio de iniciar ou expandir uma relação comercial ou um negócio. Entre os diversos contratos, o de franquia desponta como um dos mais importantes, devido à grande expansão que obteve nos últimos anos e à grande parte do mercado que domina atualmente.

Os efeitos que um contrato de franquia pode produzir são inúmeros e podem atingir diversos campos do Direito, e, sobretudo, do Direito Civil, Comercial, Internacional, Processual e Penal. Deve-se estar atento, principalmente, às questões mais polêmicas e controvertidas do Direito Internacional Brasileiro, como os casos de escolha da lei aplicável e eleição de foro. A utilização da arbitragem tem se revelado uma boa opção para resolver conflitos internacionais.

Deve-se pensar, também, ao estudar um contrato internacional de franquia, no processo de integração econômica, com a conseqüente ampliação de mercados regionais e no surgimento de um produto global padronizado para diversas regiões do mundo, tal como funciona o modelo capitalista. É através desse contrato, principalmente do modelo de master franquia, que se pode viabilizar mercados internacionais, devido a sua eficiência e adaptabilidade (de preços, variedade de produtos, forma de atendimento e etc.) a regiões de todo o mundo, que muitas vezes são diferentes e contrastantes. Dessa forma, o contrato internacional de franquia possui duas características que parecem ser contraditórias, como a padronização de um modelo de comercial e a adaptabilidade à diversidade de consumidores.

O contrato internacional de franquia se revela uma segura e eficiente opção para se expandir rapidamente uma rede de franquias em diversos 
territórios, sem realizar grandes investimentos, também é uma chance de se iniciar um negócio próprio, com uma marca forte e a garantia de que alguém irá fornecer o devido suporte para que a franquia cresça de forma bem estruturada e traga uma boa rentabilidade.

Portanto, a relação da franquia será regida pela Lei n. 8955/94 e pelas cláusulas contratuais estabelecidas, segundo o produto e o interesse das partes. As características essenciais são a independência do franqueado, exclusividade de território e objeto para exploração, que pode ser uma marca, produto ou serviço. Os principais problemas podem ser previstos no contrato: como as responsabilidades perante consumidores, o que se fazer em casos de dificuldades financeiras, ou descumprimento do contrato, quebras de patentes os casos de extinção da relação contratual.

\section{REFERÊNCIAS}

ARAÚJO, Nádia de. Contratos Internacionais e a Jurisprudência Brasileira: Lei Aplicável, Ordem Pública e Cláusula de Eleição de Foro. In: João Grandino Rodas (coord.). Contratos Internacionais. 3. ed. rev., atual. e ampl. São Paulo: Editora Revista dos Tribunais, 2002.

ASSOCIAÇÃO BRASILEIRA DE FRANCHISING (ABF); INSTITUTO FRANCHISING. Estatísticas do desempenho do franchising brasileiro em 2004. Disponível em: <http://www.portaldofranchising.com.br>. Acesso em: 12 out. 2005.

CHERTO, Marcelo Raposo. Franchising: Revolução no Marketing. São Paulo: McGraw-Hill, 1988.

CRETELLA NETO, José. Arbitragem Internacional: o Significado Peculiar do Instituto no Contexto do Mecanismo de Solução de Controvérsias da Organização Mundial do Comércio. Revista de Direito Internacional e Economia. N.ㅇ 9, out./dez. 2004.

CRETELLA NETO, José. Do Contrato Internacional de Franchising. Rio de Janeiro: Forense, 2000.

DINIZ, Maria Helena. Tratado Teórico e Prático dos Contratos. v. 4. São Paulo: Saraiva, 1996. 
MARCO, Carla Fernanda. Contrato de Franchising e seus Aspectos Internacionais. Revista Meio Jurídico. São José do Rio Preto, ano V, n.ํ50, 2001.

MENDEZ, Max de; LEHNISCH, Jean Pierre. Como fazer da franquia um bom negócio. Nobel, 1991.

MILITELLI, Marcos Aurélio. Franchising - Como Tornar sua Empresa uma Franquia. São Paulo: SEBRAE-SP, 1996.

PAULA, Luciana Marques de. O que Analisar no Pré-contrato de Franquia. Disponível em: $<$ http://www.aol.com.br/franchising/dicas/0021.adp $>$. Acesso em: 16 fev. 2006.

RODRIGUES, Sílvio. Direito Civil: dos contratos e das declarações unilaterais da vontade. 9. ed. V. 3 Editora: Saraiva. 1980.

SIMÃO FILHO, Adalberto. Franchising: Aspectos Jurídicos e Contratuais. 2. ed. São Paulo: Atlas, 1997.

STRENGER, Irineu. Arbitragem Comercial Internacional. São Paulo: LTr, 1996.

STRENGER. Irineu. Contratos Internacionais do Comércio. 4. ed. São Paulo: LTr, 2003. 